\title{
Seedling diversity and spatially related regeneration dynamics in holly woodlands and surrounding habitats
}

\author{
S. Arrieta and F. Suárez
}

Arrieta, S. and Suárez, F. 2001. Seedling diversity and spatially related regeneration dynamics in holly woodlands and surrounding habitats. - Web Ecol. 2: 38-46.

Spatial patterns of seedling distribution and diversity were analysed in small fragments of holly Ilex aquifolium L. woodlands and in their surrounding areas. Two sampling locations with similar structure were selected for this study: Oncala and Robregordo. They consist of nearly monospecific Ilex stands surrounded by grasslands with high scrub abundance.

The seedling appearance of woody species was quantified from March to November 1998. Sampled areas were: 1) closed holly canopy; 2) open holly canopy or small forest gaps; 3) holly woodland edge; 4) surrounding grassland; 5) under isolated fleshy-fruited shrubs scattered over the grassland; 6) under dry-fruited shrubs and 7) the closest forest to the holly woodland. Additionally, a pine forest at a distance of $20 \mathrm{~km}$ from Oncala was sampled. In every area ten permanent $50 \times 50 \mathrm{~cm}$ quadrats were fixed for monthly seedling control.

The highest germination density occurs under the holly woodland, especially in closed canopy areas. Nevertheless, these closed woodlands neither maintain a great quantity of surviving seedlings nor a high diversity. Seedling density is considerable in canopy gaps, shrubs and forest edge, and these habitats have greater diversity values than understorey habitats. Fleshy-fruited shrubs maintain higher seedling densities and diversity than dry-fruited shrubs. Woody seedlings are rare over the grassland. The three non-holly forests studied have very similar seedling densities and diversity values, higher than those under closed-canopy holly.

Regional differences are important for the numbers of seedlings surviving from previous years, which are scareer in Robregordo. However, little difference is observed in spatial patterns of seedling diversity between the two locations.

We discuss a number of processes affecting seed rain density and differential mortality rates that could account for these spatial patterns, namely competition for light inside the woodlands, facilitation under nurse shrubs, or competition escape at the edge. Environmental factors such as moisture stress may play a role in regional differences.

S. Arrieta (sagrario.arrieta@uam.es) and F. Suárez, Dept Interuniversitario de Ecología, Facultad de Ciencias, Univ. Autónoma, E-28049 Madrid, Spain.

The knowledge of patterns of plant distribution and diversity is essential to understand the underlying processes that govern the functioning of plant communities. Plant recruitment is the result of a series of concatenated events, including seed dissemination, germination and seedling establishment. (Harper 1977, Jordano and Herrera 1995). This seedling establishment in forest woody species is frequently related to the ability to survive in low-light environments, and the variability in shade tolerance among tree species is a key factor for understanding forest dynam- 
ics and seedling diversity (Pacala et al. 1994, Chen 1997).

Species diversity is an important topic in ecology, and a number of different theories have been proposed to explain the establishment and maintenance of diversity in communities (Tilman and Pacala 1993). Intermediate disturbance was proposed as a mechanism that enhances species coexistence by limiting competitive exclusion of dominant species. In this sense, forest gap theory appeared as an important key for the explaining of forest diversity (Hubbell et al. 1999). Microhabitat diversification in patchy environments leads to the niche partitioning theory also used for explaining some species distribution patterns (Gray and Spies 1996, Busing and White 1997). The relative importance of chance, unpredictable events, is also discussed as a motor of diversity maintenance (Brokaw and Busing 2000). Finally, some ecologists propose the concept of positive interactions and facilitation of shrubs as a mechanism of keeping diversity in water stressed environments (Pugnaire et al. 1996).

Seed dispersal by birds, colonisation of safe sites, processes of competition under a closed canopy and facilitation under nurse shrubs, detection of the regeneration windows for the different woody species: these are very important issues that need to be addressed in order to elucidate the functioning of community diversity. The understanding of diversity patterns and the processes that influence them should be at the base of any ecological forest management (Roberts and Gilliam 1995).

In the present work we study woody species seedling diversity in holly Ilex aquifolium L. woodland. This tree has an atlantic distribution in Europe, limited in the north and east by its sensitivity to prolonged frost and continental climates (Peterken and Lloyd 1967) and in the south by its edaphic moisture requirements (Blanco et al. 1997). It is a typical understorey shrub that in Spain and Portugal occurs in beech, oak and pine forests over the half-northern Iberian range. However, in some mountains of central Spain, it creates nearly monospecific woodlands, accompanied by some other tree species (Quercus pyrenaica Willd., Sorbus aria L., S. acuparia L.), shrubs (Crataegus monogyna Jacq., Viburnum lantana L., Ligustrum vulgare L.) and vines (Lonicera peryclimenum L., Ribes alpinum L., Hedera helix $\mathrm{L}$.). These small forests have been traditionally subject to rough grazing and woodcutting and they have acquired a great conservation value since holly has been considered as a protected species by regional laws.

In these areas, holly creates a closed canopy with almost no species in the understorey, due to an extremely low light availability. Nevertheless, their patchy distribution, and the abundance of ecotones, enable the maintenance of a rich woody community. This patchy structure consists of small closed holly woodlots mainly located in depressions or watercourses, surrounded by pastures. These pastures have different densities of scattered shrubs, depending on the land management experienced during the previous decades. The system as a whole seems to be very dynamic, with the presence of colonisation processes and shrub invasion on the pastures.

The aim of this study is 1) to assess the spatial distribution of woody species seedlings in these holly-woodland ecosystems, with special reference to diversity patterns and 2) to understand how these patterns differ at a regional, geographical scale.

\section{Material and methods}

\section{Study locations}

Two locations were selected for this study: Oncala (Soria, $1450 \mathrm{~m}$ a.s.l.; $\left.41^{\circ} 57^{\prime} \mathrm{N}, 2^{\circ} 20^{\prime} \mathrm{W}\right)$ and Robregordo (Madrid, $1400 \mathrm{~m}$ a.s.l.; $\left.41^{\circ} 10^{\prime} \mathrm{N}, 3^{\circ} 30^{\prime} \mathrm{W}\right)$. Oncala lies in the north face of a mountain range belonging to the "Sistema Ibérico" with a neutral substratum proceeding from sandstone and quartzite, in a region with a good development of Ilex populations (Oria de Rueda 1992). Robregordo lies on a SE facing slope, ca $150 \mathrm{~km}$ south far from Oncala, in the "Sistema Central" mountains, with more sandy soils from esquiste and gneiss. This is a southern relict population, and the woods are less developed than in the former one. Both are situated in the supramediterranean region, characterised by the presence of broad-leaved deciduous forests, especially Quercus pyrenaica.

In both sites, I. aquifolium specimens are considerably developed, with an average height of $8 \mathrm{~m}$. Therefore the morphology of the woodland is closer to that of a mediterranean forest than to the typically taller temperate forests. The studied area in Oncala has 120 ha, with three holly woodlots that occupy altogether ca 30 ha. The Robregordo area is smaller: 45 ha, with about a quarter of this being occupied by holly woodlands.

\section{Sampling procedure}

We made a stratified sampling in these two systems, defining the following sampling habitats: 1) closed holly canopy; 2) open holly canopy or small forest gaps; 3) holly woodland edge; 4) surrounding grassland; 5) the area under isolated fleshy-fruited shrubs (Rosa sp., Crataegus sp.) scattered over the grassland; 6) the area under dry-fruited shrubs (Genista sp., only sampled in Robregordo because of the virtual absence of these shrubs in Oncala) and 7) the closest forest to the holly woodland (Quercus pyrenaica Willd. in Oncala and Pinus sylvestris L. plantation in Robregordo). Additionally, a Pinus sylvestris forest $15 \mathrm{~km}$ far from Oncala was also sampled.

In each sampling habitat, ten random $50 \times 50 \mathrm{~cm}$ permanent quadrats were placed, and every seedling and new germination of woody species was identified, tagged and monthly monitored from March to early November 1998. Resprouts were not included. These were especially evi- 
dent in Rosa at the open areas and in Ilex inside the holly woodland. Their appearance was very different and easy to distinguish from the seedlings, due to the absence of cotyledons, and their much faster growth.

\section{Data analysis}

Seedlings were divided in two groups: those recently germinated seedlings (hereafter GS) and those being one or more years old (previous years seedlings, hereafter PYS). We assume that the age of PYS is between 1 and $5 \mathrm{yr}$ old. We calculated the ratio PYS:GS at quadrat scale for an age structure estimation.

Shannon's index ( $\left.\mathrm{H}^{\prime}\right)$ of diversity was calculated for every sampling quadrat and for every habitat by adding the species frequency of the ten quadrats per habitat. We made this analysis for GS and PYS separately. We used Hutcheson test for contrasting the total diversity values of each area (Magurran 1988). We made Kruskal-Wallis and Mann-Whitney nonparametric tests for comparison of diversity indices at quadrat scale and post hoc nonparametric test for multiple comparisons (Zar 1996). A significance threshold of $\alpha=0.05$ was fixed for all the statistic tests.

\section{Results}

\section{Seedling species}

Twelve species were registered in each study site, including the Pinus seedlings, only present in the pine forests (Table 1). Nine of them appeared in both systems and the other three are only present in one of them, so a total of 15 species were recorded in the study. The most common species in Oncala were $I$. aquifolium (32.5\% of seedlings), $C$. monogyna (30.3\%) and P. spinosa (8.4\%), while in Robregordo $I$. aquifolium reached $70.1 \%$ of the total number of seedlings, C. monogyna $8.6 \%$ and Rosa sp. $10.3 \%$.

\section{Seedling density}

We monitored a total of 785 seedlings, 357 in Oncala and 428 in Robregordo. Out of all the seedlings in Oncala, $30.2 \%$ of them were one or more years old, while Robregordo had only $7.8 \%$ of seedlings surviving from previous years.

Total seedling numbers and median per sampled area are reported in Table 2 . In both locations there are significant differences among areas in the total amount of recently germinated seedlings (Kruskal-Wallis $\mathrm{p}<0.01$ in Oncala and Robregordo). Multiple comparisons in Oncala indicate that all habitats have similar GS seedling density, except for the grassland and the adjacent oak-woodland, which have significantly lower densities than the other are- as. In Robregordo significant differences are found between groups of higher and lower median seedling densities, that is, closed canopy and gaps with grassland and dry-fruited shrubs. On the other hand, the density of PYS seedlings is different among areas in Oncala $(\mathrm{p}<0.01)$ but not in Robregordo $(\mathrm{p}=0.28)$, where median density was always equal to zero. With the post hoc comparisons we can infer the existence of two groups in Oncala: 1) closed and open holly woodland, grassland and fleshy-fruited shrubs with a low median density and 2) the edge of the holly woodland, oak-woodland and pine forest with a higher median density.

Comparisons of equivalent habitats between locations show significant differences only in GS density of pine forests (Mann-Whitney, $\mathrm{p}=0.02$ ) and PYS density at the edge area $(\mathrm{p}=0.02)$.

\section{PYS:GS ratio}

The mean value of the ratio between the density of older (PYS) and that of current year seedlings (GS), both in Oncala and Robregordo, was very low in closed holly woodlands but higher in open holly woodlands (Table 2). The adjacent forests and the additional pine forest showed higher mean ratio than the holly woodlands. PYS:GS ratio at the edge of the forest and under the shrubs was high in Oncala, but not in Robregordo, except under the dryfruited shrubs of this location.

\section{Diversity of recently germinated seedlings (GS)}

Spatial patterns of GS diversity are similar in both locations (Fig. 1). The highest value of total habitat diversity was recorded under fleshy-fruited shrubs, followed at the edge of the holly canopy. The lowest values were in the grassland, where almost no germination was registered, and under the closed holly woodland. The open holly woodland and the adjacent non-holly woodlands show intermediate diversity values.

In Oncala, a Hutcheson test for total diversity indices showed that the "woodland edge" and "fleshy fruited shrubs" habitats had a significantly higher Shannon diversity index than the holly woodland, both closed and open canopies, and than the oak and pine forests (Fig. 1a). When comparing values of $\mathrm{H}$ at the quadrat scale there was no significant difference of mean diversity among sampled habitats in this location (Kruskal-Wallis, $\mathrm{p}=0.07$; grasslands were not included due to few data, neither was pine forest included because of its distance from the Oncala site).

The Robregordo total diversity was significantly lower in the closed holly woodland than in all other habitats (Fig. 1b). Dry-fruited shrubs had also a significantly lower di- 


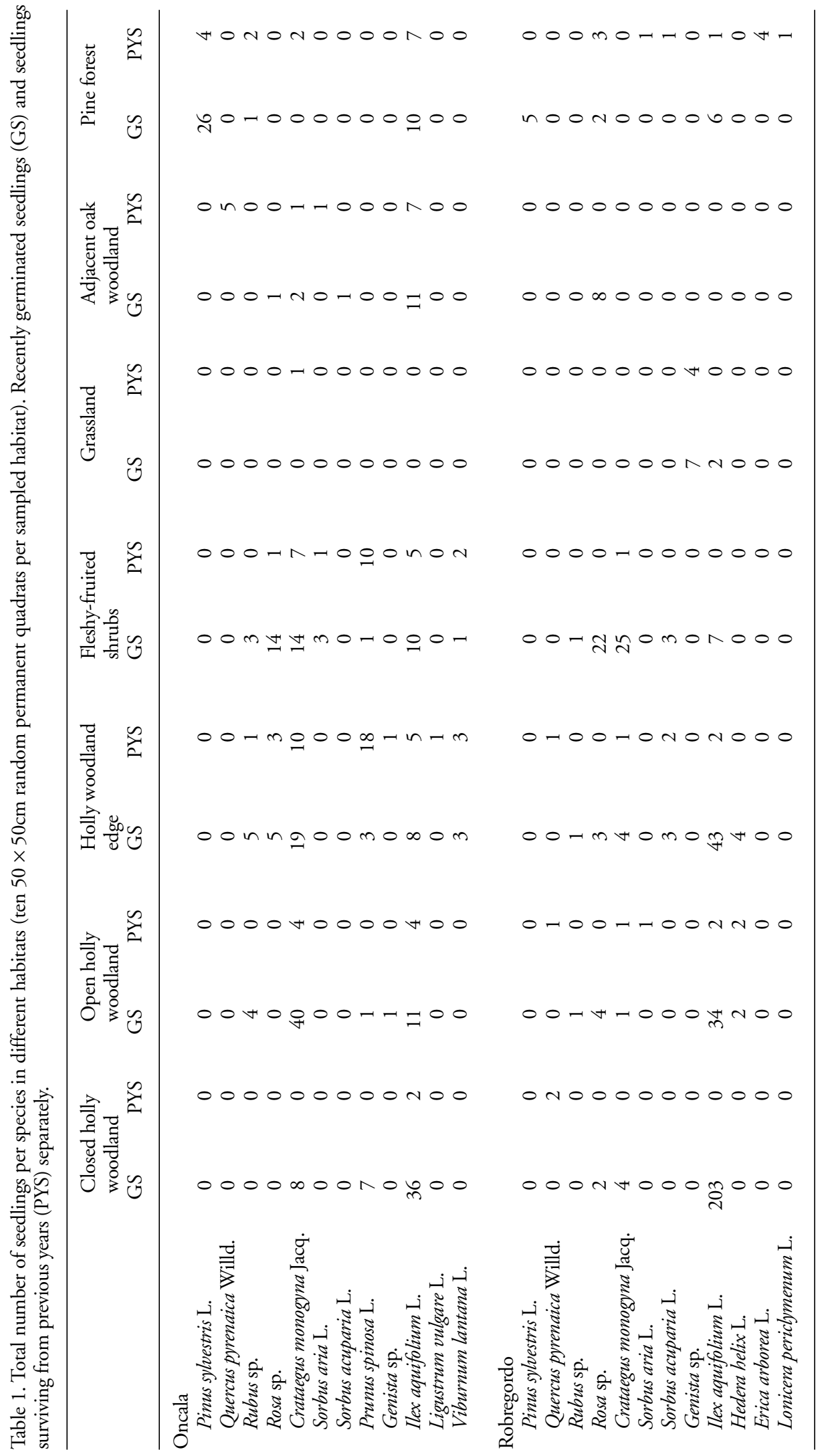




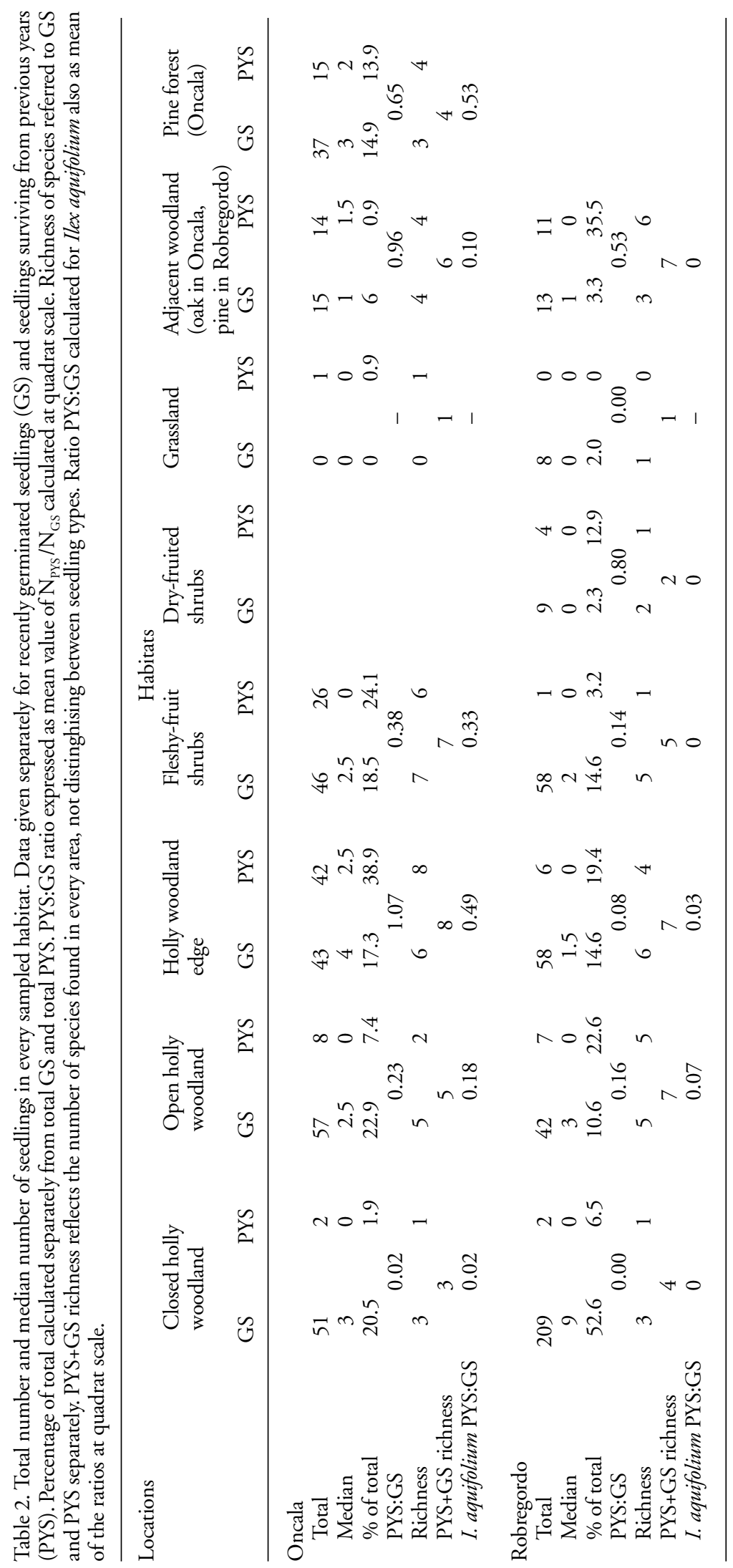


(a)

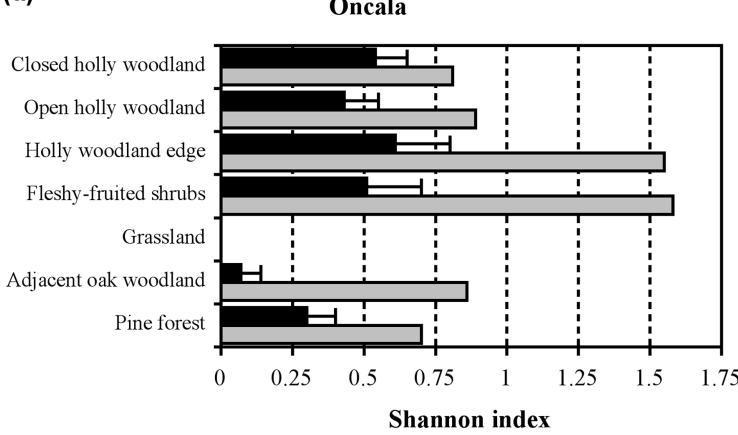

(b)

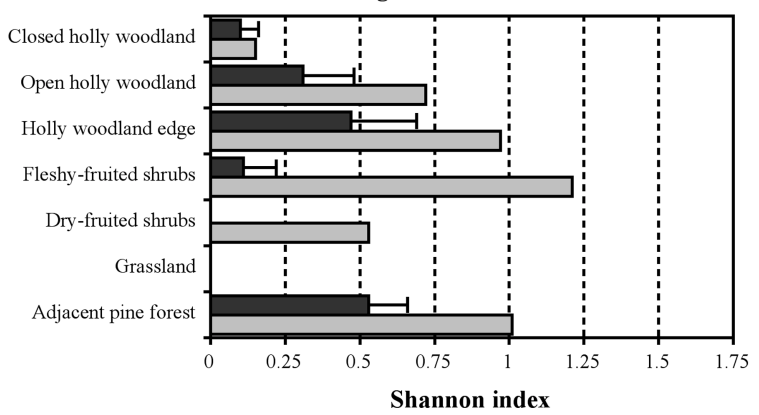

Fig. 1. Shannon diversity indices for recently germinated seedlings (GS) per sampled habitat in both locations. Black bars, mean + SE diversity index at quadrat scale. Grey bars, total habitat diversity index. If no bars are present diversity is equal to zero, except in grassland of Oncala, where no seedlings are present.

versity relative to fleshy-fruited shrubs (Hutcheson test). Average diversity at the quadrat scale did not exhibit significant differences among sampled habitats in Robregordo (Kruskal-Wallis, $\mathrm{p}=0.16$ ).

A Hutcheson test for comparison of total diversity between equivalent habitats of both locations, Oncala vs Robregordo, revealed significant diversity differences in closed holly woodlands, fleshy-fruited shrubs and woodland edges. Diversity was higher in Oncala for the three pairs. The same comparison made with the quadrat scale data revealed significant difference only for the pair of closed holly woodland (Mann-Whitney, p=0.01).

\section{Diversity of seedlings from previous years (PYS)}

The PYS seedlings' diversity was the highest at the woodland edges, open holly woodlands and at the adjacent oak and pine forests (Fig. 2). This is particularly evident in Oncala, while Robregordo had a similar pattern but with a very low presence of old seedlings under fleshy- and dryfruited shrubs.
The Hutcheson test for Oncala revealed that total diversity of PYS was significantly greater at the edge and under fleshy-fruited shrubs than in the rest of the habitats, as occurred with GS (Fig. 2a). Diversity in the closed holly woodland was significantly lower than in all other habitats. In Robregordo, the diversity of PYS was equal to zero under the closed canopy, as well as under fleshy- and dryfruited shrubs (Fig. 2b). There were no significant differences among PYS diversity of all other habitats. (Hutcheson test). There were no significant differences in the average quadrat PYS diversity among habitats, neither in Oncala (Kruskal-Wallis, $\mathrm{p}=0.10$, also excluding pine forest) nor in Robregordo ( $\mathrm{p}=0.70$ ).

Comparing equivalent habitats of both locations, there were significant differences only between total diversity values of the pairs of fleshy-fruited shrubs and open holly woodland habitats. No significant differences were found in same comparisons with quadrat scale data.

(a)

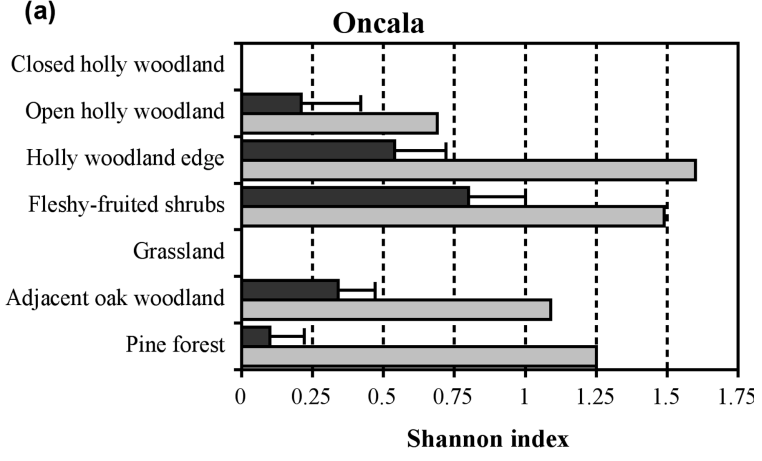

(b)

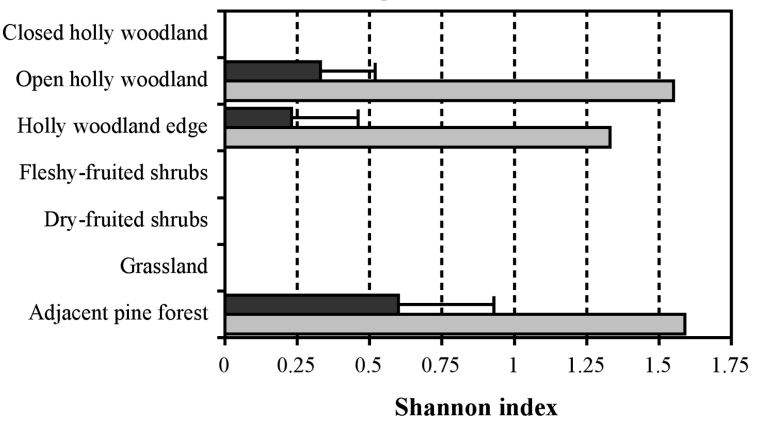

Fig. 2. Shannon diversity indices for seedlings from previous years (PYS) per sampled area in both locations. Black bars, mean + SE diversity index at quadrat scale. Grey bars, total habitat diversity index. If no bars are present, diversity is equal to zero, except in grassland of Robregordo, where no seedlings are present. 


\section{Discussion}

These results confirm the existence of spatial differences in terms of seedling density and seedling diversity. Both locations have a very similar spatial pattern in the density of recently germinated seedlings: 1) GS density is similar in holly woodlands, woodland edge and under fleshy-fruited shrubs; 2) adjacent forests support a lower quantity of seedlings than holly woodlands, and 3) the grassland and the dry-fruited shrubs support a low seedling density. Diversity patterns are also similar in both sites, and we can distinguish habitats with characteristic high and low diversity values in each location. Differences between total diversity value and mean quadrat diversity in a habitat imply that species richness increases when adding data of different samples. This is more evident in the holly woodland edge and under shrubs. This fact can explain why some local differences in diversity are not relevant at the quadrat scale, but they are important at the whole area level.

There are no differences in seedling density for both seedling groups (GS and PYS) when comparing closed and open habitats inside the holly woodland. The high GS density found in closed holly woodland in Robregordo was due to the strong local aggregation of Ilex seedlings, almost the only species germinating in this habitat. Recruitment is rather limited under the holly woodland. Nevertheless, the establishment success of seedlings is higher in the open holly woodland: different survival rates may occur between closed and open habitats, probably because of a wider intensity of light resource in the later ones. This is reflected in the PYS:GS ratio, very low in both habitats, but higher in open canopy than in closed canopy.

Differences between closed canopy and open habitats are also evident in relation with species richness and diversity. Species richness is higher under the open canopy, in both locations and for both groups of seedlings. GS diversity differences in closed vs open canopy are only clear in Robregordo, and they may reflect some dispersal limitations for those species not found under the closed woodland. Differences are enhanced at the PYS level. In fact, the diversity of these old seedlings is equal to zero (only one species per quadrat) in the closed canopy for both locations, in contrast with the higher PYS diversity values of the open areas. This promotion of diversity in forest gaps is related with the increasing in these habitats of the community-wide seedling establishment (Hubbell et al. 1999). This higher establishment probability would be accompanied by a wider range of light levels and associated niches provided in the open woodland habitat, and it could explain the higher species composition of these habitats even though their seedling density is not significantly different to that of the closed woodlands.

In holly woodland edges, proximity to the forest makes GS density similar to that of the holly woodland. PYS density at the edge in Oncala is significantly greater than inside the woodland, and PYS:GS ratio is the highest one in this location. PYS density at the edge is significantly lower in Robregordo than in Oncala. In spite of these differences between sites, in both cases diversity at the edge reaches high values for GS and PYS seedlings. This can be explained by the combination of a richer seed-rain in terms of number of species, and a higher seedling survival than those occurred in closed woodland, especially in Oncala. The rich seed rain would be reflected in the high GS richness and diversity. The different seedling survival rate accounts for the high PYS density of this location, and seems to be due to similar processes than those occurring in forest gaps, like light competition attenuation. Forest edges usually offer good opportunities for species that are normally present, but uncommon, in the interior forest (Matlack and Litvaitis 1999). Changes of species composition at the edge of the forests is not a generalised rule, but have often been described (Murcia 1995). In our study, these changes are characterised by a general enrichment of the seedling community in this edge habitat.

When we compare adjacent forests with holly woodland, we can infer that they are more similar to holly canopy gaps than to closed holly canopy in terms of seedling density and diversity. In general, GS density is lower in these forests than in closed holly woodlands, but PYS density is higher in the former. Differences are not significant when comparing seedling density and diversity of these areas with the gap areas. The differences with closed holly canopy may be due to a higher availability of light in oak and pine forests. Compared with species that cast deep shade, like holly trees, forests composed of trees that transmit more light often have increased understorey productivity (Palik and Engstrom 1999). This seedling diversity can also be explained because of the dynamic of replacement of a well developed shrub layer existing in these woodlands which is absent under the closed holly canopy. On the other hand, the studied pine forest in the Oncala region has a higher density of seedling recruitment than the pine forest of Robregordo, probably due to its being situated in a region with a higher development of forestall masses. Nevertheless, since diversity in both pine forests is similar, we can conclude that seedling diversity patterns of the three non-holly forests are similar.

Spatial patterns of seedling distribution outside the holly woodlands, that is, in grasslands and under shrubs, are very similar in both regions: high seedling density and diversity under shrubs, in sharp contrast with grasslands, where germination of woody species is merely anecdotal in our data. Fleshy-fruited shrubs reach the highest GS diversity values in both locations, and these are similar to those found at the edge of the holly woodland. GS density and GS diversity are significantly lower under dry-fruited than under fleshy-fruited shrubs in Robregordo. Nevertheless, PYS density under shrubs reaches significant values only in Oncala, whereas in Robregordo PYS density is extremely low under both types of shrubs. This is reflected in the high value of PYS:GS ratio and PYS diversity under shrubs 
in Oncala relative to Robregordo. The high PYS:GS ratio found in dry-fruited shrubs of Robregordo may be due to an exceptional aggregation of the PYS seedlings in one sampled quadrat.

Facilitation of nurse shrubs may be the clue to understanding the PYS:GS ratio under shrubs in Oncala. Fleshyfruited shrubs not only receive more seeds than adjoining grasslands (Arrieta and Suárez 1997), but also these seeds develop much faster than those arriving at the grassland (Arrieta 1999). Even though this fact has only been studied in Oncala with holly seeds, a similar phenomenon may occur with some other bird-dispersed species like Prunus spinosa, Crataegus monogyna and Viburnum lantana. This nursing effect has been demonstrated in some abandoned lands in Europe (Kollman 1995). Nevertheless, this phenomenon is not so evident in Robregordo. On one hand, higher GS diversity in fleshy-fruited shrubs compared to dry-fruited shrubs reflects a possible differential seed-rain density, probably explained by a differential utilisation of these two groups of shrubs by seed-disperser birds, that is, a post-feeding patch selection (Schupp and Fuentes 1995). On the other hand, the similar low PYS density and diversity values from these two groups of shrubs in Robregordo can be explained by the influence of external environmental factors, especially water summer stress, which seems to be restricting the possibility of woody seedling maintenance in this site.

Regional differences in seedling density (Oncala vs Robregordo) are important when analysing the generalised lower presence of PYS seedlings of any species in Robregordo, especially in habitats outside of the holly woodland, like the two groups of shrubs. Local climate, with considerable summer moisture stress, enhanced by a more sandy, water filtering substratum, could be a limiting factor for seedling survival in Robregordo. In spite of these differences, seedling diversity appears to follow a rather similar spatial pattern in both studied locations, and the results of this study are probably extrapolable to a large group of holly woodland systems of similar structure distributed all along the central mountains of Spain.

As Ilex aquifolium is a protected tree and is the main species of these woodlands, we can remark the following regeneration trends: 1) in Oncala Ilex seedlings are able to survive in almost all habitats except in grasslands, as reflected in the total number of PYS seedlings found in every habitat; recruitment success of holly seedlings in this location is higher at the edge and under shrubs; and 2) in Robregordo there is also an important amount of germinating Ilex, but in general the establishment and survival is lower in this location. Only the open holly woodland and the edge habitat had some holly PYS seedlings. These results indicate that the regeneration dynamics of Ilex aquifolium are not so different than those observed for the overall community. Even though holly is a shade-tolerant species, surviving in low light environments, it is also able to colonize environments outside the forests. What is more, young Ilex individuals are more common in the open holly woodlands, at the edge of the woodland and underneath other woody species. The regional difference observed in the whole seedling community, that is, the scarcity of seedlings surviving from previous years in Robregordo, is also important in holly recruitment, and would reaffirm the theory of a southern limitation of Ilex populations due to moisture requirements.

In the present work, we have studied the numbers of seedling, not only in forest stands, but also in different surrounding habitats. The various hypotheses raised in the introduction as possible explanations for plant diversity seem to fit well a phenomenon that occurs in all of the different microhabitats considered. Facilitation is an important process under nurse shrubs. Dispersal limitations also affect the species richness in some situations. Niche partitioning, related to the limited light resource, and intermediate disturbances, affecting to differential mortality rates, play complementary roles for diversity dynamics in most of these areas. All these theoretical approximations must be taken into account for a wide conservation strategy of these interesting holly-woodland communities.

Acknowledgements - This research was partially supported by a Ph.D. Grant of the Regional Government of Madrid. The Environmental Agency of Madrid gave us the authorisation required to work in the Robregordo field. We kindly thank all the people who helped us in the field work, and to Iris Rodriguez, José Arrieta and Sara Magalhaes for improving the English considerably. Juan Malo and Begoña Peco contributed interesting comments.

\section{References}

Arrieta, M. S. 1999. Germinación de Ilex aquifolium L. y sus implicaciones en la invasión de prados en una dehesa soriana. Actas de la XXXIX Reunión científica de la Sociedad Española para el estudio de los pastos, Almería.

Arrieta, M. S. and Suárez, F. 1997. La dispersión del acebo (Ilex aquifolium): distintas estrategias para un mismo objetivo. $-\mathrm{V}$ Jornadas de la Asociación Española de Ecología Terrestre, Córdoba.

Blanco, E. et al. 1997. Los bosques Ibéricos. Una interpretación geobotánica. - Planeta Ed., Barcelona.

Brokaw, N. and Busing, R. T. 2000. Niche versus chance and tree diversity in forest gaps. - Trends Ecol. Evol. 15: 183-188.

Busing, R. T. and White, P. S. 1997. Species diversity and smallscale disturbance in an old-growth temperate fores: a consideration of gap partitioning concepts. - Oikos 78: 562-568.

Chen, H. Y. 1997. Interspecific responses of planted seedlings to light availability in interior British Columbia: survival, growth, allometric patterns, and specific leaf area. - Can. J. For. Res. 27: 1383-1393.

Gray, A. N. and Spies, T. A. 1996. Gap size, within-gap position and canopy structure effects on conifer seedling establishment. - J. Ecol. 84: 635-645.

Harper, J. L. 1977. Population biology of plants. - Academic Press. 
Hubbell, S. P. et al. 1999. Light-gap disturbances, recruitment limitation, and tree diversity in a neotropical forest. - Science 283: 554-557.

Jordano, P. and Herrera, C. M. 1995. Shuffling the offspring: uncoupling and spatial discordance of multiple stages in vertebrate seed dispersal. - Ecosciece 2: 230-237.

Kollman, J. 1995. Regeneration window for fleshy-fruited plants during scrub development on abandoned grassland. Ecoscience 2: 213-222.

Magurran, A. E. 1988. Ecological diversity and its measurement. - Croom Helm, Cambridge.

Matlack, G. and Litvaitis, J. 1999. Forest edges. - In: Hunter, M. L. (ed.), Mantaining diversity in forest ecosystems. Cambridge Univ. Press, pp. 210-233.

Murcia, C. 1995. Edge effects in fragmented forests: implications for conservation. -Trends Ecol. Evol. 10: 58-62.

Oria de Rueda, J. A. 1992. Las acebedas de Castilla y León y La Rioja: origen, composición y dinámica. - Ecología 6: 79-91.

Pacala, S. W. et al. 1994. Sapling growth as a function of resources in a north temperate forest. - Can. J. For. Res. 24: 2172 2183.
Palik, B. and Engstrom, R. T. 1999. Species composition. - In: Hunter, M. L. (ed.), Mantaining diversity in forest ecosystems. Cambridge Univ. Press, pp. 65-94.

Peterken, G. F. and Lloyd, S. 1967. Biological flora of the British Isles. Ilex aquifolium. - J. Ecol. 55: 841-858.

Pugnaire, F. I. et al. 1996. Facilitation and succession under the canopy of a leguminous shrub, Retama sphaerocarpa, in a semi-arid environment in south-east Spain. - Oikos 76: 455464.

Roberts, M. K. and Gilliam, F. S. 1995. Patterns and mechanisms of plant diversity in forested ecosystems: implications for forest management. - Ecol. Appl. 5: 969-977.

Schupp, E. W. and Fuentes, M. 1995. Spatial patterns of seed dispersal and the unfication of plant population ecology. Ecoscience 2: 267-275.

Tilman, D. and Pacala, S. W. 1993. The maintenance of species richness in plant communities. - In: Ricklefs, R. E. and Schluter, D. (eds), Species diversity in ecological communities. Historical and geographical perspectives. Univ. of Chicago Press.

Zar, H. 1996. Biostatistical analysis. - Prentice-Hall. 